\title{
WHAT ARE THE FUTURE ENERGY ISSUES TO BE SOLVED BY ENERGY TECHNOLOGY?
}

\author{
YOUAH LEE ${ }^{1}$, SUNGJUN HONG ${ }^{1} \&$ HYOUN JONG KIM ${ }^{2}$ \\ ${ }^{1}$ Korea Institute of Energy Research 152, South Korea \\ ${ }^{2}$ WIPS, DMC Tower, South Korea
}

\begin{abstract}
The purpose of this study is to find issues that can be solved by energy technologies. In this study, future energy reports and R\&D projects are analyzed using keyword ranking and clustering methodologies. New energy technologies are emerging as an optimal means of sustainable development, addressing climate change and energy demand issues. The number of investments in the development of energy technologies is also increasing. Generally, the planning of R\&D in the energy sector focuses on technologies that are proposed by researchers in a bottom-up manner. These methods have limitations that sometimes prevent them from leading to new, innovative technologies. Therefore, it is necessary to introduce an R\&D planning process that focuses on the problems to be solved. Firstly, future prospect reports published by EWG, Gartner, IBM, Davos, MIT, KISTI and KISTEP were analyzed. The keyword analysis results from 2012 to 2017 show that "systems", "Nano", and "batteries" are the most common words. In order to see the most recent trends, the data from 2016 to 2017 was then analyzed. "Intelligence" and "system" were found to appear frequently. The results thus show that the main keywords have recently changed. Secondly, R\&D projects conducted by Horizon 2020 were analyzed by the same methodology. These organizations are representative R\&D funding agencies in the EU, which is world leaders in energy technology. Keyword analysis results show that "energy", "innovative", "efficient”, "system" and "sustainable" are the most common words. Thirdly, keyword clustering analysis showed that "local energy system", "smart grid energy", "smart building”, "zero energy building", and "thermal energy storage building" were highly related. Finally, the latest issues were reinforced through a news search and interviews with experts. As a result, we have identified eight major energy issues to be solved by energy technologies. The contribution of this study is to propose a different $\mathrm{R} \& \mathrm{D}$ planning approach focusing on problem oriented R\&D issues.

Keywords: energy technology, $R \& D$ planning, keyword ranking, keyword networking.
\end{abstract}

\section{INTRODUCTION}

The development of new energy technologies is essential for our sustainable development. Recently the importance of the energy technology field has been highlighted, due to such issues as climate change, the 4th industrial revolution and technology convergence. This is causing drastic changes to its R\&D environment. At the COP21 climate summit in Paris, 20 countries announced their goals to double their clean energy R\&D investment by 2020. Thus it is important to focus $R \& D$ planning in order to select promising core technologies on which to concentrate investment. The existing planning methodology in the R\&D field uses a bottom-up approach, in which $R \& D$ is centered on subjects proposed by researchers. $R \& D$ planning, in accordance with a roadmap and policy requirements, has its limits when it comes to pre-emptively and effectively responding to future issues.

A top-down R\&D planning approach is an alternative that can overcome the limits of the bottom-up strategy. A top-down plan, consists of several steps; issue selection, the suggestion of solutions to the problem, the definition of the problem, and the support of tasks. Its core processes look into the current research around the issue and seek alternative solutions in accordance with the defined problem. The conditions and challenges associated with potential solutions, and their various alternatives may be considered. Ultimately, a problemsolving R\&D approach can pre-emptively respond to the issues of the future. Top-down 
planning has its merits because it can flexibly and elastically resolve linear risks, which may be encountered during the $R \& D$ planning process. These include the risk of errors in prediction, which can occur in a case where the $R \& D$ path, as set out in a roadmap, is modified or changed due to technological innovation.

The DOE in the USA, EUREKA in Europe and others are already pushing forward their $R \& D$ subject plan through prediction of the future. They suggest that identifying the current core issues in the pertinent fields or industries is the most important step. Fraunhofer in Germany is run based on industrial demands and has also recently pushed forward an R\&D plan in which they identify relevant research subjects and define problems in accordance with their own predictions of the future market. The Korean government has also started utilizing problem-solving fusion R\&D planning processes. This is centered on the National Science and Technology Research Council which has 25 government-funded research institutes as its members. They are working to identify R\&D subjects with high public interest, to resolve such social problems as fine dust, the disposal of nuclear waste and water shortages.

However, top-down study planning steps have never been applied to R\&D in the energy field. In this study, a methodology that can be used to identify the core current issues is introduced, and the analysis results when it is applied to three issues in the field of energy technology are presented.

In section 2, we present the methodologies which can be applied to identify current issues, the keyword ranking and clustering methods are introduced, and the characteristics of the analysis material which were reviewed in this study are explained. In section 3, the analysis results of both a report on the prospects of the future and the R\&D programs of Horizon 2020 in Europe are explained, along with the resulting issues.

\section{HOW TO ANALYZE ENERGY TECHNOLOGY ISSUES}

\subsection{Analysis method}

In this study, we applied keyword ranking and keyword clustering methods, based on text mining, to draw out the technologies which the energy field should successfully develop. Keyword ranking analysis may be defined as determining the number of times a word appears in a document. Many studies in the fields of bibliometric analysis and scientific metrology have utilized this method to determine the study trends in a specific field. Therefore, our first step was to apply this technique, which is the basis of the text mining analysis method.

Word clustering analysis is utilized to determine the associations between certain words through the method of text mining. This is done to find the main themes of the collected documents. Its application has recently been expanded to R\&D planning. Seo et al. [1], applied this method to domestic R\&D trends. Oh [2], applied a related method to determine study opportunities in the traffic ICT fusion field.

The pointwise mutual information (PMI) method is applied to the results of a clustering analysis. The association of words means the number of cases where a certain two words appear in the text corpus. The PMI is defined in eqn (1), where $\mathrm{P}(\mathrm{x})$ and $\mathrm{P}(\mathrm{y})$ stand for the probabilities that words $\mathrm{x}$ and $\mathrm{y}$ will appear, and $\mathrm{P}(\mathrm{x}, \mathrm{y})$ is the joint probability of them appearing, or the probability that they will appear at the same time.

$$
P M I(x, y)^{n}=\log \frac{P(x, y)}{P(x) P(y)}
$$




\subsection{Data collection}

In order to analyze the issues that energy technologies have to resolve, we established a database of promising future technologies, selected by major institutes. The institutes were selected from among those which are prominent in technology analysis, and which have continually presented promising future technologies. Seven institutes - EWG, Gartner, BM, KISTEP, KISTI, MIT and WEF - were selected for analysis. The database (DB) covers the period from 2012 to 2017. In order to analyze the R\&D programs carried out by advanced countries, we analyzed the Horizon 2020 support projects. The EU's Framework program, which started in 1984, ended with FP7 (2007-2013). Since then the EU has been pushing forward its Horizon 2020 program, which began in 2014. The new program was planned to promote Europe's knowledge-based economy, and resolve various problems facing mankind. About 78.6 billion euro is planned to be invested in the program for the seven years from 2014 through 2020 [3].

Out of the total of 11,069 projects supported by Horizon 2020, we analyzed 1,247, those centered on energy and the environment. This excluded the projects related to employment, investment, health and markets in Europe. Out of its total investment of 25,137 million dollars, 6,423 million dollars was spent on these projects, accounting for about $26 \%$ of the total.

Table 1: Number of future technologies in the database.

\begin{tabular}{|l|c|c|c|c|c|c|c|}
\hline Institutes & 2012 & 2014 & 2015 & 2016 & 2017 & Continue & Total \\
\hline EWG & & & & & & 5 & 5 \\
\hline Gartner & & & & 10 & 10 & & 20 \\
\hline IBM & & 5 & 5 & & 5 & & 15 \\
\hline KISTEP & 652 & & 10 & 10 & 9 & & 681 \\
\hline KISTI & & 10 & 11 & 10 & & 590 & 621 \\
\hline MIT & & & 10 & 10 & 10 & & 30 \\
\hline WEF & & 10 & 10 & 10 & & & 30 \\
\hline Total & 652 & 25 & 46 & 50 & 34 & 595 & 1,402 \\
\hline
\end{tabular}

Table 2: Horizon 2020 project (Energy and Environment).

\begin{tabular}{|l|l|c|c|}
\hline Code & Horizon 2020 project & Number & $\begin{array}{c}\text { Project amount } \\
\text { (Million\$) }\end{array}$ \\
\hline $\begin{array}{l}\text { H2020- } \\
\text { EU.3.2. }\end{array}$ & $\begin{array}{l}\text { Food Security, Sustainable Agriculture and } \\
\text { Forestry, Marine, Maritime and Inland } \\
\text { Water Research and the Bioeconomy }\end{array}$ & 215 & $1,169.98$ \\
\hline $\begin{array}{l}\text { H2020- } \\
\text { EU.3.3. }\end{array}$ & Secure, Clean and Efficient Energy & 338 & $2,195.41$ \\
\hline $\begin{array}{l}\text { H2020- } \\
\text { EU.3.4. }\end{array}$ & Smart, Green and Integrated Transport & 351 & $1,964.10$ \\
\hline $\begin{array}{l}\text { H2020- } \\
\text { EU.3.5. }\end{array}$ & $\begin{array}{l}\text { Climate Action, Environment, Resource } \\
\text { Efficiency and Raw Materials }\end{array}$ & 343 & $1,193.97$ \\
\hline
\end{tabular}




\section{RESULTS}

\subsection{Analysis of future perspective reports}

We performed a keyword ranking analysis on 1,420 promising technologies, selected by the seven institutes between 2012 and 2017. The analysis results show that "system", "nano" and "battery" appeared most frequently. The keyword "battery" appears very frequently in promising future technologies, not just those restricted to the field of energy. Thus, it is clear that batteries are important to the diffusion of new renewable energy technologies and the resultant system stability.

In order to determine the latest trends, we performed an analysis on 84 promising future technologies for the period from 2016 to 2017. The keyword "intelligence (artificial)", which ranked 35th in the overall analysis, took the first place, while "System", which ranked first in the overall analysis, took the second place. This means that, with the 4th industrial revolution recently being stressed, these trends reflect the technologies being dealt with in the future perspective reports by various institutes.

In order to find the connections between artificial intelligence, the 4th industrial revolution, IoT, ICT technology and energy technology, we searched the latest news. In the data collected from news reports on energy and artificial intelligence, we obtained; "smart grids-efficient, power-cheaper, building-zero energy, efficiency-internet of things, consumption-information, efficiency-energy, storage-peak shaving, prices-digitally appwholesale model-changes price, and manufacturing-energy saving”.

The data collected from the latest news on energy and the 4th industrial revolution yielded; "smart, digital, power, efficient, control, analysis, smart-grid, building, manufacture, IoT, IoE, energy-resource, and light”. Clearly there is a partial overlap between these two results.

Table 3: Analysis results of keyword ranking (2012-2017).

\begin{tabular}{|l|l|l|l|l|l|l|l|l|}
\hline No. & Keyword & Frequency & No. & Keyword & Frequency & No. & Keyword & Frequency \\
\hline 1 & System & $119(8.5 \%)$ & 6 & Production & $60(4.3 \%)$ & 11 & Artificiality & $45(3.2 \%)$ \\
\hline 2 & Nano & $88(6.3 \%)$ & 7 & Energy & $59(4.2 \%)$ & 12 & Fuel & $44(3.1 \%)$ \\
\hline 3 & $\begin{array}{l}\text { Electronic } \\
\text { battery }\end{array}$ & $71(5.1 \%)$ & 8 & Life & $53(3.8 \%)$ & 13 & $\begin{array}{l}\text { Power } \\
\text { generation }\end{array}$ & $43(3.1 \%)$ \\
\hline 4 & Environment & $64(4.6 \%)$ & 9 & Automation & $51(3.6 \%)$ & 14 & Living body & $41(2.9 \%)$ \\
\hline 5 & Battery & $64(4.6 \%)$ & 10 & Efficiency & $49(3.5 \%)$ & 15 & Heredity & $30(2.1 \%)$ \\
\hline
\end{tabular}

Table 4: Analysis results of keyword ranking (2016-2017).

\begin{tabular}{|l|l|l|l|l|l|l|l|l|}
\hline No & Keyword & Frequency & $\begin{array}{l}\text { No } \\
\text {. Keyword }\end{array}$ & Frequency & No & Keyword & Frequency \\
\hline 1 & $\begin{array}{l}\text { Intelligence } \\
\text { (artificial) }\end{array}$ & $9(10.7 \%)$ & 6 & $\begin{array}{l}\text { Environment } \\
\text { (restoration, } \\
\text { change, } \\
\text { response) }\end{array}$ & $4(4.8 \%)$ & 11 & $\begin{array}{l}\text { Recycling } \\
\text { /reuse/w } \\
\text { aste }\end{array}$ & $3(3.6 \%)$ \\
\hline 2 & System & $7(8.3 \%)$ & 7 & Autonomy & $4(4.8 \%)$ & 12 & Internet & $3(3.6 \%)$ \\
\hline 3 & Thing & $5(6 \%)$ & 8 & $\begin{array}{l}\text { Artificial } \\
\text { intelligence }\end{array}$ & $4(4.8 \%)$ & 13 & Heredity & $3(3.6 \%)$ \\
\hline 4 & Security & $5(6 \%)$ & 9 & Architecture & $4(4.8 \%)$ & 14 & $\begin{array}{l}\text { Block } \\
\text { chain }\end{array}$ & $3(3.6 \%)$ \\
\hline 5 & $\begin{array}{l}\text { loT / } \\
\text { loT botnet }\end{array}$ & $5(6 \%)$ & 10 & Battery/fuel & $3(3.6 \%)$ & 15 & $\begin{array}{l}\text { Mesh } \\
\text { app }\end{array}$ & $3(3.6 \%)$ \\
\hline
\end{tabular}


(a)
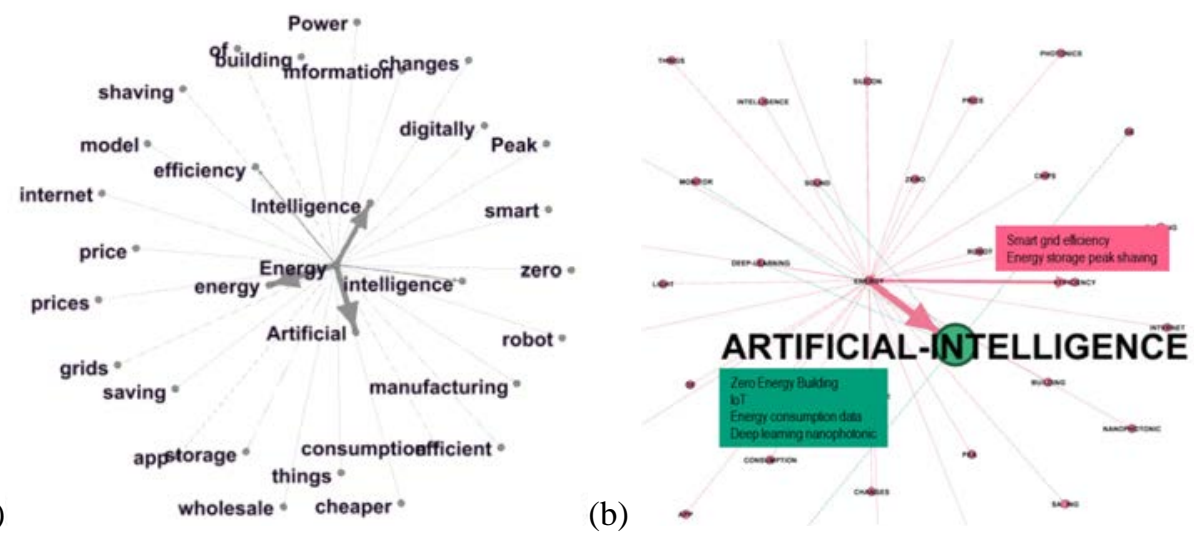

Figure 1: (a) News searching for energy with artificial-intelligence; (b) News searching for energy, IOT, and ICT.

We found that most of the keywords obtained are particularly focused on the improvement of energy efficiency.

The major keywords collected from the news related to energy, IoT and information and communications technology (ICT) were; "smart-city, smart-home, smart-industry, smartbuilding, energy, efficient, power, converter, sensor, security, AI, save, hospital, heat, plants, lifecycle-management, consumption, optimize, health, helping, living, self-driving, car, and smart-campus”. From the search, we obtained information on the power sources of IoT instruments, applied in diverse fields from a smart home to a smart campus, as well as the energy efficiency of such power sources. As a result of the data collection from the news reports on energy and ICT, we obtained; "artificial-intelligence, peak shaving, intelligence robot, deep-learning, smart grids, building zero energy, consumption information, and efficient”.

\subsection{Analysis results for R\&D programs (Horizon 2020).}

The keyword ranking analysis results for the 1,247 projects shows that "energy" (frequency 186(4.2\%)), “innovative” (frequency 163(3.7\%)), “efficient” (frequency 161(3.7\%)), "system" (frequency 153(3.5\%)) and "sustainable" (frequency 131(3\%)) appear most frequently.

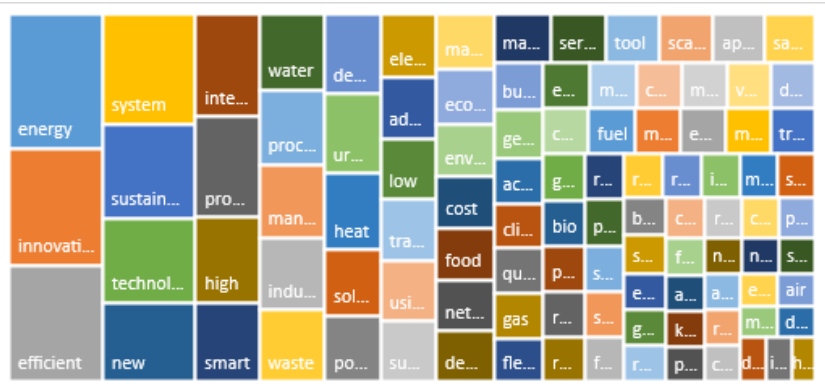

Figure 2: Analysis result for the Horizon 2020 programs. 
(a)

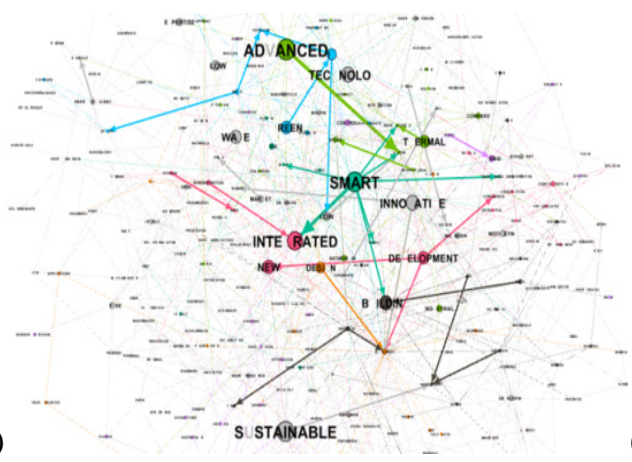

(b)

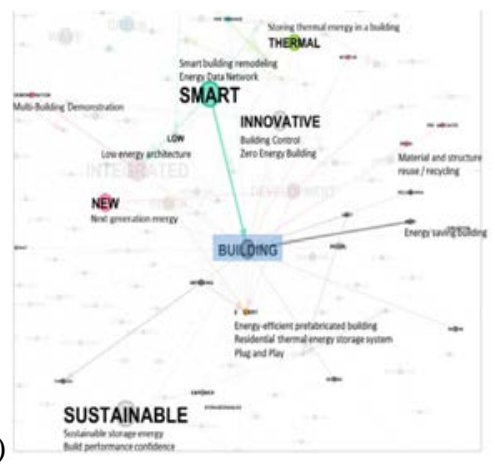

Figure 3: (a) Clustering pf keywords from Horizon 2020 (excluding 'energy'); (b) Clustering of keywords from Horizon 2020 for "building”.

When examining the clustering of keywords, it is not only the rankings against the whole which are analyzed, but also specific results regarding related technologies. The results of the clustering analysis using the main keywords, excluding "energy", shows that "smart", "advanced", "integrated" and "sustainable" are all highly associated.

When we performed additional smart association keyword analysis for the above keywords, "local energy system”, "smart grid energy", "smart building” and many other phrases were detected. When we reanalyzed the associated keywords of "building", it was found to be part of a main cluster of keywords including; "smart", "construction material of waste", "technology related to material and structural material recycling", "energy efficiency”, "zero energy building”, "building for the storage of heat energy”, and others.

\subsection{Determination of current issues}

The latest issues are reinforced through the news search and interviews with experts. In the news search, we found the latest trends related to each keyword and analyzed the problems that the energy technologies would have to resolve. It became clear that the words which appeared to have a high priority were actually being implemented. We also reviewed the appropriateness of the selected current issues, and the association between the keywords, with ten experts in energy technologies. As a result, we have identified three major energy issues to be resolved by energy technologies.

\section{CONCLUSIONS}

In this study, we have determined the current issues relating to energy technologies which must be resolved. For this purpose, we analyzed promising future technologies and R\&D tasks being carried out as part of Horizon 2020. We applied the keyword ranking and keyword clustering methods, in order to analyze promising future technology reports. We established a database of 1,420 technologies, selected by major institutes between 2012 and 2017. The analysis results show that "system", "nano" and "battery" appeared most frequently from 2012 to 2017. In the more recent period, from 2016 to 2017, the keywords “artificial intelligence”, "system”, and "security” appeared most frequently.

In order to determine which keywords are most recently being stressed, and the fusion of different fields of technology with energy, we additionally performed keyword clustering 
Table 5: Issues of energy technology.

\begin{tabular}{|c|c|c|c|}
\hline Subject & Current Issue & Grounds for selection of issue & Keywords \\
\hline $\begin{array}{l}\text { Environmentally- } \\
\text { friendly } \\
\text { transportation } \\
\text { means }\end{array}$ & $\begin{array}{l}\text { Development of } \\
\text { advanced mobility } \\
\text { technology which will be } \\
\text { a game changer in the } \\
\text { next-generation } \\
\text { transportation field. }\end{array}$ & $\begin{array}{l}\text { As demand increases for electric vehicles, } \\
\text { hydrogen vehicles and personal short- } \\
\text { distance transportation means (electric } \\
\text { wheels, drones, etc.), It is necessary to } \\
\text { develop the core technologies of; weight } \\
\text { lightening of batteries, quick charging, } \\
\text { weight lightening and high durability. }\end{array}$ & $\begin{array}{l}\text { Development of } \\
\text { electric } \\
\text { vehicles/hybrid } \\
\text { vehicles/hydrogen } \\
\text { vehicles } \\
\text { storage; battery; cloud. }\end{array}$ \\
\hline Smart building & $\begin{array}{l}\text { Development of } \\
\text { technologies for smart } \\
\text { building control, applying } \\
\text { the core technologies of } \\
\text { the } 4^{\text {th }} \text { industrial } \\
\text { revolution, such as AI } \\
\text { and IoT. }\end{array}$ & $\begin{array}{l}\text { Technology development is necessary for } \\
\text { prediction and optimization of } \\
\text { demand/supply of energy for buildings, } \\
\text { based on behavior of residents, utilizing AI, } \\
\text { IoT, big data and machine learning. }\end{array}$ & $\begin{array}{l}\text { Appearance of } \\
\text { buildings; zero energy } \\
\text { buildings } \\
\text { IoT; low-power } \\
\text { sensor; } \\
\text { energy; power } \\
\text { rectifier. }\end{array}$ \\
\hline $\begin{array}{l}\text { Sustainable energy } \\
\text { generation } \\
\text { technology }\end{array}$ & $\begin{array}{l}\text { Technology development } \\
\text { for innovative reduction } \\
\text { of the costs associated } \\
\text { with new renewable } \\
\text { energy so as to achieve } \\
\text { grid parity. }\end{array}$ & $\begin{array}{l}\text { Technology development for early } \\
\text { realization of grid parity for renewable } \\
\text { energy technologies, such as sunlight, wind } \\
\text { and biomass power generation, fuel cells, } \\
\text { geothermal heat and tidal power, to } \\
\text { promote the diffusion of new renewable } \\
\text { energy sources and secure global technical } \\
\text { competitiveness. }\end{array}$ & $\begin{array}{l}\text { Solar heat } \\
\text { smart; new renewable } \\
\text { energy; storage; } \\
\text { battery; cloud. }\end{array}$ \\
\hline
\end{tabular}

analysis based on news searches. We found that such keywords as "energy efficiency", "power supply to IoT instruments", "smart grid", and "zero energy consumption" were stressed. In the keyword ranking of Horizon 2020 projects, "energy" and "innovation efficiency" were found to be the major keywords. The keyword clustering analysis results show that such keywords as "smart", "zero energy" and "building" are highly associated. Finally, the current issues that those keywords are trying to resolve were drawn through news search and interview of experts.

This study assessed the possibility of applying a top-down process to R\&D planning in the energy field. We determined that the method of drawing issues based on data mining can be applied to this aim. However, once the keywords were drawn it is not easy to connect them to the problem-oriented current issues. In this study, we compiled relevant stories through both the news search and consultation with experts. Such a qualitative approach has its limits, since the opinions of the experts can influence it to a large extent. In future studies, an effective methodology to draw current issues, centered on keywords, will be necessary.

This study focused on the first step of drawing out current issues through a top-down process. In a follow-up study, it will be necessary to examine the processes for defining problems in order to resolve each issue with energy technologies, and the ways in which we draw out core values. It is expected that the outcomes of this analysis can be effectively applied to direct R\&D and thus resolve social problems.

\section{ACKNOWLEDGEMENT}

This work was conducted under framework of the research and development program of the Korea Institute of Energy Research (B7-2462). 
22 Energy and Sustainability VII

\section{REFERENCES}

[1] Seo, W., Yoon, J. \& Park, H., An exploratory study on the Korean National R\&D trends using co-word analysis. Journal of Information Technology Applications \& Management, 19(4), pp. 1-18, 2012.

[2] Oh, J., Identifying research opportunities in the convergence of transportation and ICT using text mining techniques. Transportation Research, 22(4), pp. 93-110, 2015.

[3] Horizon 2020, https://ec.europa.eu/programmes/horizon2020/en/what-horizon-2020. 